\title{
Direct Synthesis and Catalytic Applications of Ordered Large Pore Aminopropyl-Functionalized SBA-15 Mesoporous Materials
}

\author{
Xueguang Wang, Kyle S. K. Lin, Jerry C. C. Chan, and Soofin Cheng* \\ Department of Chemistry, National Taiwan University, Taipei 106, Taiwan
}

Received: September 16, 2004; In Final Form: November 4, 2004

\begin{abstract}
SBA-15 mesoporous silica has been functionalized with aminopropyl groups through a simple co-condensation approach of tetraethyl orthosilicate (TEOS) and (3-aminopropyl)triethoxysilane (APTES) using amphiphilic block copolymers under acidic conditions. The organic-modified SBA-15 materials have hexagonal crystallographic order, pore diameter up to $60 \AA$, and the content of aminopropyl groups up to $2.3 \mathrm{mmol} \mathrm{g}{ }^{-1}$. The influences of TEOS prehydrolysis period and APTES concentration on the crystallographic order, pore size, surface area, and pore volume were examined. TEOS prehydrolysis prior to the addition of APTES was found essential to obtain well-ordered mesoporous materials with amino functionality. The amount of APTES incorporated in the silica framework increased with the APTES concentration in the synthesis gel, while the ordering of the mesoporous structure gradually decreased. Analysis with TG, IR, and solid state NMR spectra demonstrated that the aminopropyl groups incorporated in SBA-15 were not decomposed during the preparation procedure and the surfactant P123 was fully removed through ethanol extraction. The modified SBA-15 was an excellent base catalyst in Knoevenagel and Michael addition reactions.
\end{abstract}

\section{Introduction}

Since the discovery of ordered mesoporous silicates M41S, $, 1,2$ a variety of ordered mesoporous materials have been synthesized using the surfactant templating method. To expand the applications of mesoporous silica in catalysis, ${ }^{3-5}$ separation, ${ }^{6,7}$ and sensor design, ${ }^{8}$ many researches have focused on the preparation of organic-functionalized materials by the direct incorporation of organic groups through co-condensation or by grafting the organic groups onto the surface of the mesoporous silica. ${ }^{9-21}$ The co-condensation method is often preferred to the postsynthesis pathway because it minimizes processing steps and provides a more uniform distribution of the organic functionalities. ${ }^{22}$ In addition, one-pot co-condensation synthesis often provides a higher loading of organic functionalities without closing the framework mesopores. ${ }^{23}$

Aminopropyl-functionalized mesoporous silica have been found to be useful for some base-catalyzed reactions ${ }^{23}$ or further postsynthesis functionalization. ${ }^{24,25} \mathrm{Up}$ to now, most of the work was on the modification of the small mesopores of MCM-type silica, which was synthesized under basic conditions, or on HMS-type silica, which was synthesized under neutral conditions. ${ }^{20,26}$ As to the large mesoporous silica synthesized using amphiphilic block copolymers under acidic conditions, to the best of our knowledge, only disordered materials were obtained by co-condensation of tetraethyl orthosilicate (TEOS) and (3aminopropyl)triethoxysilane (APTES). ${ }^{27,28}$ It was proposed that the protonated amine groups would interfere with the selfassembly of the copolymer pore-directing agent and the silica precursor under the strong acidic condition. ${ }^{27}$ That prompts us to report in this paper the results that we have synthesized highly ordered SBA-15 mesoporous silica containing aminopropyl groups up to $2.28 \mathrm{mmol} \mathrm{g}^{-1}$, with high surface area and narrow pore size distribution, by an improved one-pot method using

* Corresponding author. Fax: +886-2-23636359. E-mail: chem1031@ ntu.edu.tw. triblock copolymer Pluronic P123 $\left(\mathrm{EO}_{20} \mathrm{PO}_{70} \mathrm{EO}_{20}\right)$ as poredirecting agent under a strong acidic condition. The obtained materials were characterized by FTIR, $\mathrm{N}_{2}$ adsorption-desorption measurement, TG, TEM, solid state ${ }^{29} \mathrm{Si} \mathrm{NMR}$, and elemental analysis (EA). The material was found to be an efficient base catalyst in Knoevenagel reactions of carbonyl compounds with ethyl cyanoacetate and the reactions of the aldol condensation and subsequent intramolecular Michael addition of benzaldehyde and 2'-hydroxyacetophenone to flavanone.

\section{Experimental Section}

2.1. Chemicals and Synthesis. Surfactant $\mathrm{P} 123\left(\mathrm{EO}_{20} \mathrm{PO}_{70^{-}}\right.$ $\mathrm{EO}_{20}, M_{\mathrm{av}}=5800$ ) was purchased from Aldrich and other chemicals of reagent grade were from Acros. All chemicals were used as received.

Aminopropyl-functionalized SBA-15 materials (denoted as SBA- $\mathrm{NH}_{2}$ ) were prepared by a one-pot synthesis method. Pluronic $123(4 \mathrm{~g})$ was dissolved in $125 \mathrm{~g}$ of $2.0 \mathrm{M} \mathrm{HCl}$ solution at room temperature. After TEOS was added, the resultant solution was equilibrated at $40{ }^{\circ} \mathrm{C}$ for prehydrolysis, and then APTES was slowly added into the solution. The molar composition of the mixture was $(1-x)$ TEOS: $x$ APTES:6.1 HCl:0.017 P123:165 $\mathrm{H}_{2} \mathrm{O}$, where $\mathrm{x}$ varied from 0 to 0.20 , or APTES/(TEOS + APTES $)=0-20 \%$. The resulting mixture was stirred at 40 ${ }^{\circ} \mathrm{C}$ for $20 \mathrm{~h}$ and then transferred into a polypropylene bottle and reacted at $90{ }^{\circ} \mathrm{C}$ under static condition for $24 \mathrm{~h}$. The solid product was recovered by filtration and dried at room-temperature overnight. The template was removed from the assynthesized material by refluxing in $95 \%$ ethanol for $24 \mathrm{~h}(1.5$ $\mathrm{g}$ of as-synthesized material per $400 \mathrm{~mL}$ of ethanol). Finally, the material was filtered, washed several times with water and ethanol, and dried at $50{ }^{\circ} \mathrm{C}$.

2.2. Sample Characterization. $X$-ray powder diffraction (XRD) patterns were obtained on a PANalytical X'Pert Pro diffractometer using $\mathrm{Cu} \mathrm{K} \alpha$ radiation $(\lambda=1.5418 \AA)$ at $45 \mathrm{kV}$ 
and $40 \mathrm{~mA}$. The data were collected from 0.5 to $5^{\circ}(2 \theta)$ with a resolution of $0.02^{\circ}$.

$\mathrm{N}_{2}$ adsorption-desorption isotherms were measured using Micromeritics Tristar 3000 at liquid nitrogen temperature. Before the measurements, the samples were degassed at $100{ }^{\circ} \mathrm{C}$ for 12 h. The specific surface areas were evaluated using the BrunauerEmmett-Teller (BET) method in the $P / P_{0}$ range $0.05-0.3$. Pore size distribution curves were calculated using the adsorption branch of the isotherms and the Barrett-Joyner-Halenda (BJH) method, and pore sizes were obtained from the peak positions of the distribution curves. The pore volume was taken at the $P / P_{0}=0.990$ single point

Thermogravimetric (TG) analyses were carried out on a $\mathrm{Du}$ Pont 951 thermogravimetric analyzer with a heating speed of $10{ }^{\circ} \mathrm{C} / \mathrm{min}$ under air in a flow of $50 \mathrm{~mL} / \mathrm{min}$. $\mathrm{N}$ elemental analyses (EA) were performed on a Heraeus CHNS elemental analyzer. Fourier transform infrared (FTIR) was carried on a Nicolet Magna-IR 550 spectrometer with a resolution of $2 \mathrm{~cm}^{-1}$ using the $\mathrm{KBr}$ method. Transmission electron microscopy (TEM) was performed on a Hitachi H-7100 electron microscope, operating at $75 \mathrm{kV}$.

The NMR experiments were carried out at ${ }^{29} \mathrm{Si},{ }^{13} \mathrm{C}$, and ${ }^{1} \mathrm{H}$ frequencies of 59.6, 75.5, and $300.1 \mathrm{MHz}$, respectively, on a Bruker DSX300 NMR spectrometer equipped with a commercial $4 \mathrm{~mm}$ MAS NMR probe. All spectra were measured at room temperature. The magic-angle spinning frequencies were set to $6 \mathrm{kHz}$ for all experiments, and the variation was limited to \pm 3 $\mathrm{Hz}$ using a commercial pneumatic control unit. Chemical shifts were externally referenced to TMS for ${ }^{29} \mathrm{Si}$ and ${ }^{13} \mathrm{C}$. For the ${ }^{29} \mathrm{Si}$ Bloch-decay experiment, the number of the scan was set to 3072 and the recycle delay was set to $60 \mathrm{s.}{ }^{29} \mathrm{Si}\left\{{ }^{1} \mathrm{H}\right\}$ and ${ }^{13} \mathrm{C}\left\{{ }^{1} \mathrm{H}\right\}$ cross-polarization spectra were measured with a recycle delay of $5 \mathrm{~s}$, and the contact times were $3 \mathrm{~ms}$. The scan number was 5120. During the contact time the ${ }^{1} \mathrm{H}$ nutation frequency was set equal to $50 \mathrm{kHz}$, and a linear ramping was applied to the nutation frequencies of ${ }^{29} \mathrm{Si}(33.6-46.8 \mathrm{kHz})$ and ${ }^{13} \mathrm{C}(27.3-$ $43.0 \mathrm{kHz})$. The proton decoupling field during the acquisition period was $83 \mathrm{kHz}$.

2.3. Catalytic Reactions. Before the reaction, the aminopropyl-functionalized materials were treated with tetramethylamonium hydroxide (TMAOH) to remove the residue $\mathrm{Cl}^{-}$ions and to neutralize the protonated amine groups in the sample. One gram of the modified sample was suspended in $50 \mathrm{~mL}$ of $0.2 \mathrm{M}$ methanol solution of TMAOH at room temperature for $30 \mathrm{~min}$. The solid was recovered by filtration, washed with methanol, and finally dried at $120^{\circ} \mathrm{C}$ for 1 day. All the catalytic reactions were carried out under $\mathrm{N}_{2}$ in a flask that was equipped with a reflux condenser and a magnetic stirrer. The reactor was placed in a thermostat bath. In a typical experiment, the reactants were mixed in a solvent and heated to the set temperature, and then $0.15 \mathrm{~g}$ of the dried catalyst was rapidly added into the reactor. After the reaction, the catalyst was separated by filtration. The products were analyzed using a Chrompak CP 9000 gas chromatograph (GC) equipped with $30 \mathrm{~m} \times 0.32 \mathrm{~mm}$ RTX-50 capillary column and FID detector. Individual reaction product was identified by GC-mass spectrometry (HP5971 mass spectrometer connected with a $30 \times 0.25 \mathrm{~mm}$ RTX-50 capillary column).

\section{Results and Discussion}

3.1. Functionalized SBA-15 with Aminopropyl Groups. Small-angle X-ray diffraction patterns of as-synthesized and ethanol extracted materials are shown in Figure 1. The diffraction patterns of the extracted samples, both the pure siliceous

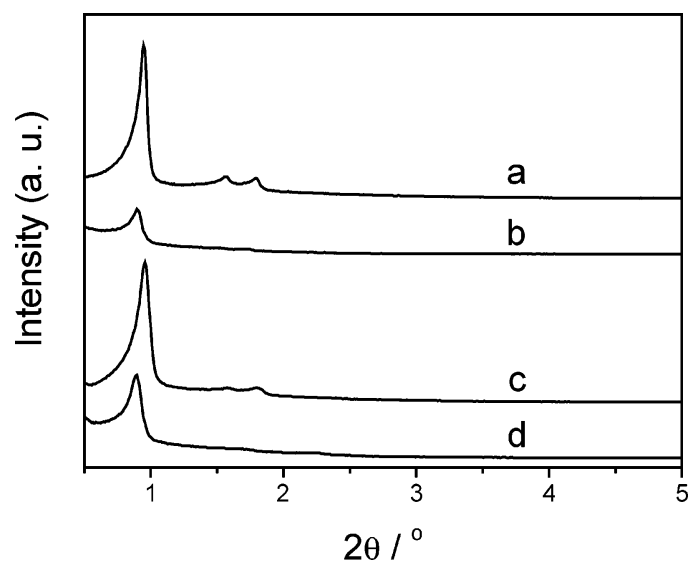

Figure 1. X-ray diffraction patterns of (a) extracted pure SBA-15, (b) as-synthesized pure SBA-15, (c) extracted $10 \% \mathrm{SBA}-\mathrm{NH}_{2}$, and (d) as-synthesized $10 \% \mathrm{SBA}-\mathrm{NH}_{2}$.

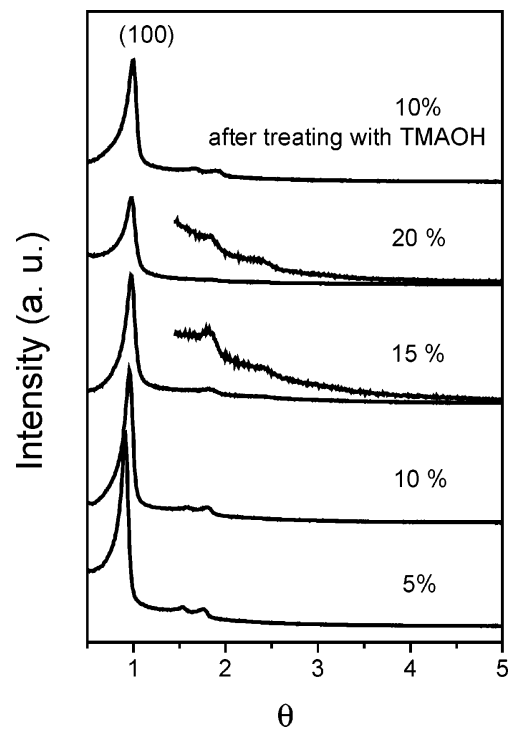

Figure 2. XRD patterns of the extracted $\mathrm{SBA}-\mathrm{NH}_{2}$ materials with different APTES contents in the initial mixture and the extracted $10 \%$ $\mathrm{SBA}-\mathrm{NH}_{2}$ after treating with TMAOH.

SBA-15 and the amino-functionalized $\mathrm{SBA}-\mathrm{NH}_{2}$ materials, exhibit stronger intensities than the corresponding as-synthesized ones. That is due to the enhanced contrast in the electron density after the removal of copolymer surfactant from the matrixes. ${ }^{29,30}$ The extracted samples show one intense diffraction indexed to (100) plane and two well-resolved weak diffraction peaks corresponding to (110) and (200) planes, indicating that the crystallographic ordering of the mesopores is retained on extraction with ethanol. However, the slight shift of the diffraction peaks of the extracted materials toward larger $2 \theta$ angles (Figure 1) indicates a slight shrinkage of the cell dimension.

XRD patterns of the extracted SBA- $\mathrm{NH}_{2}$ materials are shown in Figure 2. All the samples synthesized with different concentrations of APTES show one intense (100) peak and weak peaks of (110) and (200) diffraction. The patterns were similar to that of pure siliceous SBA-15, indicating that the prepared SBA$\mathrm{NH}_{2}$ materials contain well-ordered hexagonal arrays of onedimensional channel structure. ${ }^{31}$ However, the peak intensity decreases and the higher order (110) and (200) diffractions become less resolved when the APTES molar contents in the synthesis gel is increased to $20 \%$, showing that the mesopore ordering decreases with the APTES content. A similar phenomenon was also observed by Tatsumi et al. ${ }^{20}$ in the synthesis 


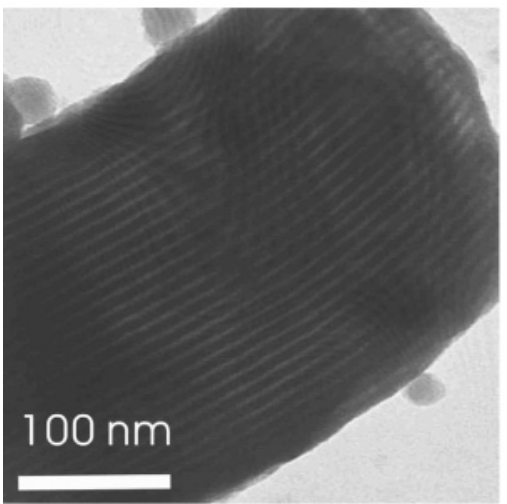

(a)

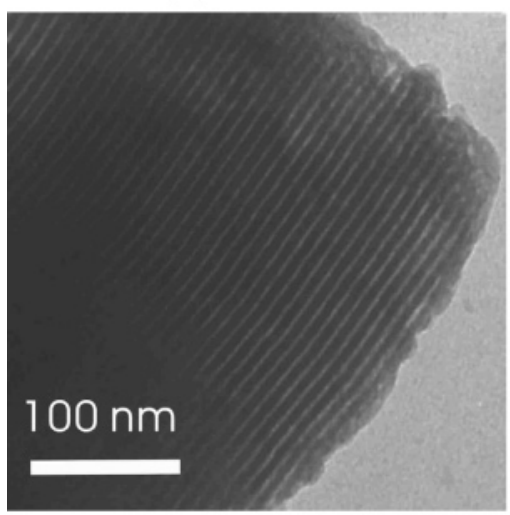

(c)

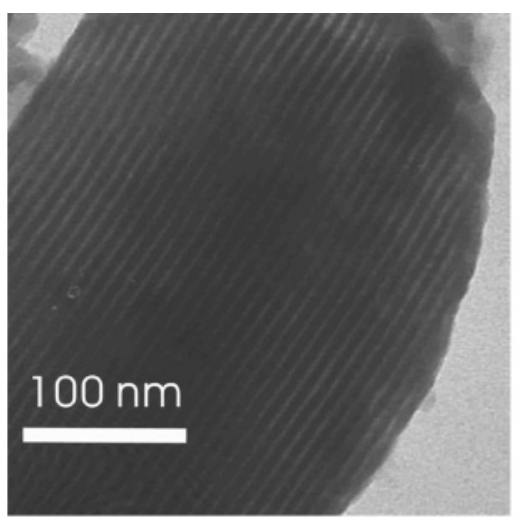

(b)

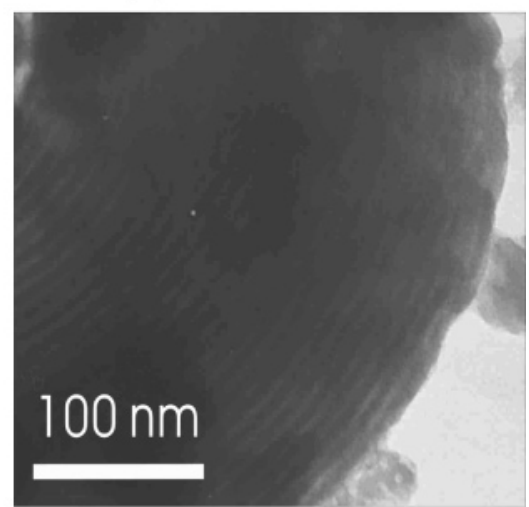

(d)

Figure 3. Transmission electron micrographs of the extracted SBA-15 mesoporous silica functionalized with different APTES concentrations in the initial mixture: (a) $0 \%$, (b) $10 \%$, (c) $15 \%$, and $20 \%$.

TABLE 1: Physicochemical Properties of the Extracted Functionalized Materials with APTES Concentrations in the Initial Mixture and the Extracted Pure SBA-15

\begin{tabular}{lccccc}
\hline \multicolumn{1}{c}{ sample } & $\begin{array}{c}D_{100} \\
\text { spacing }(\AA)\end{array}$ & $\begin{array}{c}\text { pore } \\
\operatorname{diam}^{a}(\AA)\end{array}$ & $\begin{array}{c}S_{\mathrm{BET}} \\
\left(\mathrm{m}^{2} / \mathrm{g}\right)\end{array}$ & $\begin{array}{c}\text { pore vol } \\
\left(\mathrm{cm}^{3} / \mathrm{g}\right)\end{array}$ & $\begin{array}{c}\text { wall } \\
\text { thickness }(\AA)\end{array}$ \\
\hline pure SBA-15 & 93 & 78 & 769 & 1.04 & 29.9 \\
$5 \% \mathrm{SBA}-\mathrm{NH}_{2}$ & 97 & 73 & 723 & 0.96 & 39.0 \\
$10 \% \mathrm{SBA}-\mathrm{NH}_{2}$ & 92 & 67 & 664 & 0.85 & 39.5 \\
$15 \% \mathrm{SBA}-\mathrm{NH}_{2}$ & 91 & 59 & 443 & 0.53 & 46.0 \\
$20 \% \mathrm{SBA}-\mathrm{NH}_{2}$ & 91 & 57 & 290 & 0.38 & 48.3
\end{tabular}

of aminopropyl-functionalized MCM-41. The phenomenon was explained by that APTES would perturb the self-assembly of surfactant micelles and the silica precursor. The physicochemical and textural properties of the $\mathrm{SBA}-\mathrm{NH}_{2}$ materials with different concentrations of APTES are summarized in Table 1 . The $d_{100}$ spacing of the extracted materials decreases from 96.7 to 90.8 $\AA$ as the APTES concentration in the synthesis gel increases from $5 \%$ to $20 \%$, indicating that the presence of APTES did affect the self-assembly process and shrink the cell dimension of the resultant mesoporous materials. Nevertheless, the TEM micrographs confirm that the $\mathrm{SBA}-\mathrm{NH}_{2}$ materials contain wellordered, one-dimensional pore structure, similar to that of the extracted pure SBA-15 (Figure 3).

Elemental and thermogravimetric analyses were carried out to determine the amount of APTES incorporated in SBA-15. The TG profiles of the as-synthesized and ethanol extracted samples of $\mathrm{SBA}-\mathrm{NH}_{2}$ with $10 \%$ APTES in the synthesis mixture and that of as-synthesized pure SBA-15 are illustrated in Figure 4. For the as-synthesized $\mathrm{SBA}-\mathrm{NH}_{2}$ sample, the $2 \%$ weight loss at temperature lower than $100{ }^{\circ} \mathrm{C}$ is attributed to the loss of small amount of adsorbed water. The $8-10 \%$ weight loss at $160-250{ }^{\circ} \mathrm{C}$ is mainly due to the decomposition of copolymer surfactant, and it disappears on the ethanol extracted

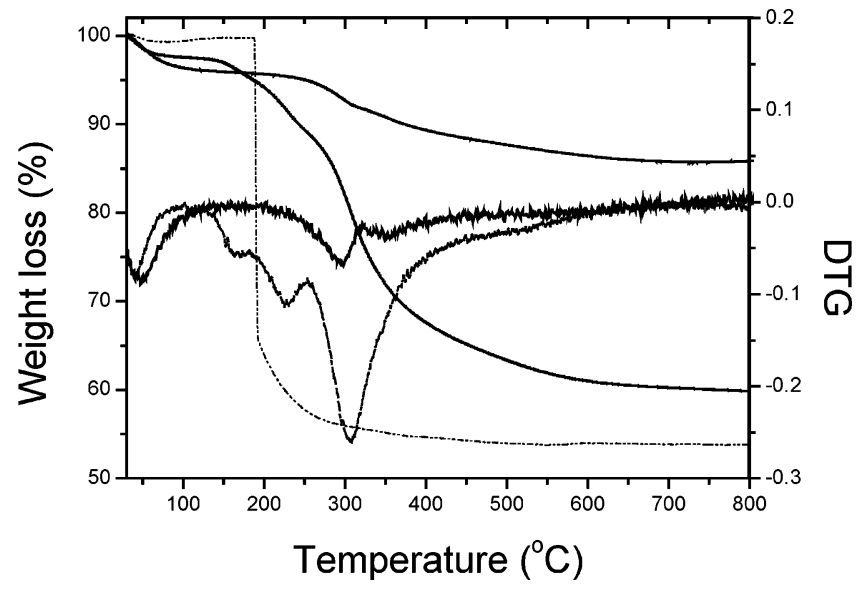

Figure 4. TGA and DTG profiles of the as-synthesized pure siliceous SBA-15 (dash dot dot), the as-synthesized (dash), and the extracted (solid) functionalized SBA-15 with $10 \%$ aminopropyl groups in the initial mixture.

sample. Immediately following is a large weight loss of 20$25 \%$ at $250-500{ }^{\circ} \mathrm{C}$. For the extracted sample, this weight loss at $250-500{ }^{\circ} \mathrm{C}$ is much less $(8-10 \%)$ and probably attributed to the decomposition of aminopropyl groups incorporated in $\mathrm{SBA}-\mathrm{NH}_{2}$. The DTG profile shows two peaks in this temperature region, indicating that the aminopropyl groups may be decomposed stepwise upon heating in air. As to the large weight loss at $250-500{ }^{\circ} \mathrm{C}$ for the as-synthesized $\mathrm{SBA}-\mathrm{NH}_{2}$, more than half of it should be contributed from the decomposition of surfactant template. In comparison to the decomposition temperature of the surfactant on pure siliceous SBA-15, the surfactants probably interact with the wall of $\mathrm{SBA}-\mathrm{NH}_{2}$ more strongly. Besides, both the as-synthesized and the extracted 


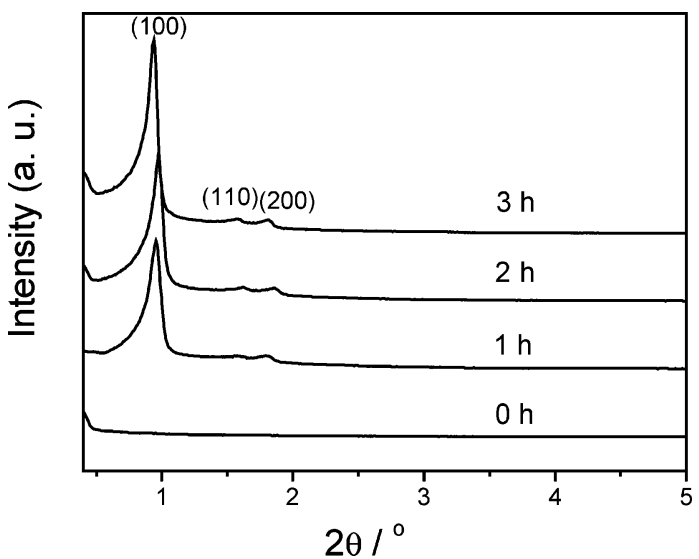

Figure 5. XRD patterns of the extracted $10 \% \mathrm{SBA}-\mathrm{NH}_{2}$ with different TEOS prehydrolysis periods.

TABLE 2: Incorporation of Organic Groups in Extracted Aminopropyl-Functionalized SBA-15

\begin{tabular}{|c|c|c|c|c|}
\hline \multirow[b]{2}{*}{ sample } & \multicolumn{2}{|c|}{$\mathrm{N}$ content $(\mathrm{mmol} / \mathrm{g})$} & \multirow{2}{*}{$\begin{array}{c}\text { theoretical } \\
\text { content }(\mathrm{mmol} / \mathrm{g})\end{array}$} & \multirow{2}{*}{$\begin{array}{l}\text { incorporation } \\
\text { ratio }(\%)\end{array}$} \\
\hline & by EA & $\overline{\text { by TG }}$ & & \\
\hline $5 \% \mathrm{SBA}-\mathrm{NH}_{2}$ & 0.48 & 0.77 & 0.80 & 60 \\
\hline $10 \% \mathrm{SBA}-\mathrm{NH}_{2}$ & 1.21 & 1.31 & 1.54 & 78 \\
\hline $15 \% \mathrm{SBA}-\mathrm{NH}_{2}$ & 1.85 & 1.89 & 2.22 & 83 \\
\hline $20 \% \mathrm{SBA}-\mathrm{NH}_{2}$ & 2.28 & 2.40 & 2.86 & 80 \\
\hline
\end{tabular}

samples exhibit $1-3 \%$ weight loss above $500{ }^{\circ} \mathrm{C}$. These are likely due to the dehydroxylation of the silicate networks ${ }^{32}$ or the elimination of residual ethoxy groups because of incomplete hydrolysis of TEOS. ${ }^{27}$

The elemental analysis results are shown in Table 2. In general, about $80 \%$ of the aminopropyl groups from APTES are effectively incorporated in the SBA-15 framework. That value implies that APTES is more difficult than TEOS to condensate into the silica framework. The relatively low incorporation percentage $(60 \%)$ for sample $5 \% \mathrm{SBA}-\mathrm{NH}_{2}$ is most likely due to experimental error upon introducing the small amount of APTES into the synthesis gel. The amino group contents analyzed by TG are slightly higher than those by EA. This may be due to that the condensation of silanol groups is in similar temperature range as that for the decomposition of aminopropyl groups.

The prehydrolysis of TEOS prior to the addition of APTES was found a key step in preparing aminopropyl-functionalized SBA-15 of ordered structure using P123 as pore-directing agent under acidic condition. Figure 5 shows the XRD patterns of the ethanol extracted $10 \% \mathrm{SBA}-\mathrm{NH}_{2}$ with different prehydrolysis periods. It can be seen that the sample without prehydrolysis of TEOS is X-ray amorphous. When the TEOS prehydrolysis time reaches to $1 \mathrm{~h}$, one intense peak indexed to (100) reflection and higher order weak (110) and (200) reflections appear. The intensity of the diffraction peaks increases with the prehydrolysis time, indicating more ordered mesoporous structure was formed. Interestingly, no precipitate was observed in the mixture of TEOS and APTES at $40{ }^{\circ} \mathrm{C}$ under acid condition if TEOS was not prehydrolyzed. In a subsequent aging period at $90{ }^{\circ} \mathrm{C}$, only transparent gel was formed, which is different from those reported in the synthesis of mesoporous amine-functionalized silica under neutral and basic conditions. ${ }^{20,26,33}$ That can be explained by the following reasons. On one hand, the protonated aminopropyl groups may interfere in the self-assembly of the copolymer surfactant and the silica precursors. On the other hand, the protonated amine groups probably interact with the ethoxy groups of TEOS strongly through hydrogen bond so that the hydrolysis and
TABLE 3: Physical Properties and Amino Groups Contents of the Extracted 10\% $\mathrm{SBA}-\mathrm{NH}_{2}$ with Different Prehydrolysis Periods

\begin{tabular}{cccccc}
\hline $\begin{array}{c}\text { prehydrolysis } \\
\text { period (h) }\end{array}$ & $\begin{array}{c}D_{100} \\
\text { spacing }(\AA)\end{array}$ & $\begin{array}{c}\text { pore } \\
\operatorname{diam}^{a}(\AA)\end{array}$ & $\begin{array}{c}S_{\mathrm{BET}} \\
\left.\mathrm{m}^{2} / \mathrm{g}\right)\end{array}$ & $\begin{array}{c}\text { pore vol } \\
\left(\mathrm{cm}^{3} / \mathrm{g}\right)\end{array}$ & $\begin{array}{c}\mathrm{N} \text { content by } \\
\mathrm{EA}(\mathrm{mmol} / \mathrm{g})\end{array}$ \\
\hline 0 & & & 447 & 0.26 & 1.28 \\
1 & 92 & 67 & 664 & 0.85 & 1.21 \\
2 & 91 & 65 & 573 & 0.75 & 1.23 \\
3 & 94 & 69 & 593 & 0.79 & 1.23 \\
4 & 89 & 63 & 412 & 0.60 & 1.33 \\
6 & 89 & 63 & 459 & 0.63 & 1.34
\end{tabular}

condensation of ethoxysilane are inhibited. Therefore, by prehydrolysis of TEOS in the presence of P123 and acid, the surfactant micelles can assemble with TEOS without the perturbation from aminopropyl groups.

The $\mathrm{SBA}-\mathrm{NH}_{2}$ materials prepared with TEOS prehydrolysis for 1-6 h all exhibited type IV isotherms with $\mathrm{H} 1$ hysteresis loops. As to the sample prepared without TEOS prehydrolysis, no apparent hysteresis loop was observed. It is shown in Table 3 that the $10 \% \mathrm{SBA}-\mathrm{NH}_{2}$ prepared with TEOS prehydrolysis for $1-3 \mathrm{~h}$ display much higher surface areas and larger pore volumes than that without prehydrolysis. However, if the prehydrolysis period was lengthened to $4 \mathrm{~h}$ or longer, the surface area, pore volume, and pore diameter of the resultant SBA$\mathrm{NH}_{2}$ decreased. Elemental analyses indicate that the amount of aminopropyl groups incorporated in the silica framework is independent of the prehydrolysis period in the range of $1-3 \mathrm{~h}$, whereas the nitrogen content increases slightly with longer prehydrolysis period. Based on these results, prehydrolysis of TEOS for longer than $3 \mathrm{~h}$ is probably not a suitable condition to prepare aminopropyl-functionalized SBA-15. In such a condition, the surfactant-silica assembly formed by TEOS condensation may be too compact to allow APTES to diffuse freely into the soft area and condensation. Instead, APTES would concentrate near the pore mouth and partially block the pores. Because the $\mathrm{SBA}-\mathrm{NH}_{2}$ samples prepared by prehydrolysis of TEOS for $1 \mathrm{~h}$ gave the greatest surface area and pore volume, the materials studied hereafter were prepared under this condition.

$\mathrm{N}_{2}$ adsorption-desorption isotherms of $\mathrm{SBA}-\mathrm{NH}_{2}$ with different aminopropyl contents are shown in Figure 6. The samples prepared with up to $10 \%$ APTES have steep increase in adsorption at $P / P_{0}=0.6-0.8$, indicating that the obtained materials possess similar large mesopores and narrow pore-size distribution as that of pure SBA-15. On the other hand, samples with $15 \%$ and $20 \%$ APTES have apparently lower absorption volume and narrower pore diameter. Moreover, the $\mathrm{BJH}$ pore diameter, BET surface area, and pore volume of $\mathrm{SBA}-\mathrm{NH}_{2}$ decrease with the increase in aminopropyl content, as shown in Table 1. These results are attributed to the occupation of large organic molecules on the surface of the pores as well as the perturbation of aminopropyl groups during the silicate condensation process.

FTIR spectra of the aminopropyl-functionalized SBA-15 are illustrated in Figure 7. For the as-synthesized sample, the absorbance peaks corresponding to the $\mathrm{C}-\mathrm{H}$ stretchingand bending vibrations appear in the range of 2850-3000 and 1460 $\mathrm{cm}^{-1}$, respectively. Those at 1377 and $1350 \mathrm{~cm}^{-1}$ are assigned to the stretchs of $\mathrm{C}-\mathrm{O}-\mathrm{C}$ on $\mathrm{P} 123$. These peaks became negligible on the extracted materials, indicating that the surfactant in the as-synthesized materials was almost completely removed upon extraction with ethanol. In all the materials, the typical $\mathrm{Si}-\mathrm{O}-\mathrm{Si}$ bands around $1220,1070,801$, and $473 \mathrm{~cm}^{-1}$ associated with the formation of a condensed silica network are present, but weak peaks associated with noncondensed $\mathrm{Si}-$ 

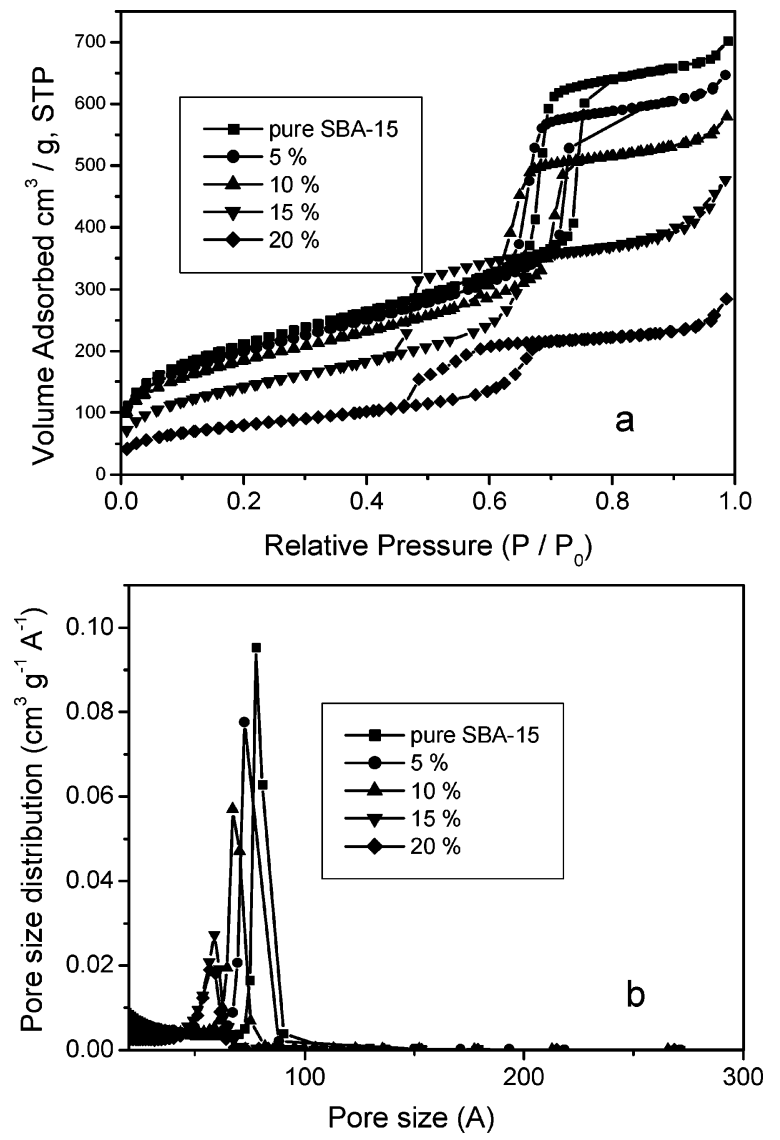

Figure 6. Nitrogen adsorption-desorption isotherms (a) and BJH pore size distribution plots (b) of the extracted $\mathrm{SBA}-\mathrm{NH}_{2}$ materials with different APTES concentrations in the initial mixture.

$\mathrm{OH}$ groups in the range of $940-960 \mathrm{~cm}^{-1}$ were also present. ${ }^{19}$ The gradual shift of the $\mathrm{Si}-\mathrm{OH}$ band toward lower wavenumber (from 960 to $944 \mathrm{~cm}^{-1}$ ) as the APTES concentration increases is probably due to the increase in interaction between the $-\mathrm{NH}_{2}$ groups and the silanol groups through hydrogen bonding. ${ }^{34}$ The presence of $\mathrm{N}-\mathrm{H}$ bending vibration around $687 \mathrm{~cm}^{-1}$ and the symmetric $-\mathrm{NH}_{2}$ bending vibration at $1510 \mathrm{~cm}^{-1}$ confirms the incorporation of amino groups. It is also shown in Figure 7 that the intensity of these peaks increases with aminopropyl content. The absorbance of the $\mathrm{C}-\mathrm{N}$ stretching vibration is normally observed around $1000-1200 \mathrm{~cm}^{-1} \cdot{ }^{35}$ However, this peak cannot be resolved due to its overlap with the absorbance of $\mathrm{Si}-\mathrm{O}-$ $\mathrm{Si}$ stretch in the $1000-1130 \mathrm{~cm}^{-1}$ range and that of $\mathrm{Si}-\mathrm{CH}_{2}-\mathrm{R}$ stretch in the $1200-1250 \mathrm{~cm}^{-1}$ range. ${ }^{27,36}$ The presence of aminopropyl groups in the modified SBA-15 was further corroborated by a broad band at $2700-3400 \mathrm{~cm}^{-1}$, attributed to the $\mathrm{NH}_{3}{ }^{+}$stretching vibration, and by the increases of its intensity with the aminopropyl content. The strong peak around $1630 \mathrm{~cm}^{-1}$ is mainly from the bending vibration of adsorbed $\mathrm{H}_{2} \mathrm{O}$.

The successful incorporation of APTES in functionalized SBA-15 mesoporous materials is confirmed by NMR spectroscopy. ${ }^{29} \mathrm{Si}$ CP-MAS NMR spectra of all the extracted SBA$\mathrm{NH}_{2}$ materials in Figure 8 show three distinct resonance peaks corresponding to $\mathrm{Q}^{n}\left(\mathrm{Q}^{n}=\mathrm{Si}(\mathrm{OSi})_{n}(\mathrm{OH})_{4-n}, n=2-4 ; \mathrm{Q}^{4}\right.$ at $\delta$ $=-111 \mathrm{ppm}, \mathrm{Q}^{3}$ at $\delta=-101 \mathrm{ppm}$, and $\mathrm{Q}^{2}$ at $\left.\delta=-92 \mathrm{ppm}\right)$ and two more peaks assigned to $\mathrm{T}^{m}\left(\mathrm{~T}^{m}=\mathrm{RSi}(\mathrm{OSi})_{m}(\mathrm{OH})_{3-m}\right.$, $m=1-3 ; \mathrm{T}^{3}$ at $\delta=-67 \mathrm{ppm}$ and $\mathrm{T}^{2}$ at $\left.\delta=-58 \mathrm{ppm}\right) .{ }^{19,37}$ The appearance of $\mathrm{T}^{m}$ peaks confirms that the silane organic moieties were incorporated as a part of the silica wall structure. Solid state ${ }^{29} \mathrm{Si}$ MAS NMR spectra of the extracted $10 \%$ and $20 \% \mathrm{SBA}-\mathrm{NH}_{2}$ are illustrated in Figure 9. The relative integrated intensities of the $\mathrm{T}^{m}$ and $\mathrm{Q}^{n}$ signals $\left(\mathrm{T}^{m} /\left(\mathrm{T}^{m}+\mathrm{Q}^{n}\right)\right)$ are 0.12 and 0.22 , respectively, in good agreement with those theoretically expected on the basis of the composition of APTES in the initial mixture, showing that the amount of organicfunctionalized moieties in the silica wall structures increases with APTES concentration in the starting mixture. It should be noticed that the relative ratio of $\mathrm{Q}^{3} / \mathrm{Q}^{4}$ intensities also increases with APTES concentration $\left(0.43\right.$ for $10 \% \mathrm{SBA}-\mathrm{NH}_{2}$ and 0.65 for $20 \% \mathrm{SBA}-\mathrm{NH}_{2}$ ), revealing that the addition of APTES has the effect of interfering the complete condensation of silanol groups in TEOS. ${ }^{13} \mathrm{C}$ CP-MAS NMR spectrum (Figure 10) of the ethanol extracted sample with $10 \%$ amino groups clearly displays three peaks at 10,21 , and $42 \mathrm{ppm}$, corresponding to the $\mathrm{C}$ atoms on the $\mathrm{Si}-\mathrm{CH}_{2}-\mathrm{CH}_{2}-\mathrm{CH}_{2}-\mathrm{NH}_{2}$ group in sequence from left to right. ${ }^{28}$ It further confirms that the SBA$\mathrm{NH}_{2}$ material was indeed functionalized with aminopropyl groups and the organic moiety was not decomposed during the
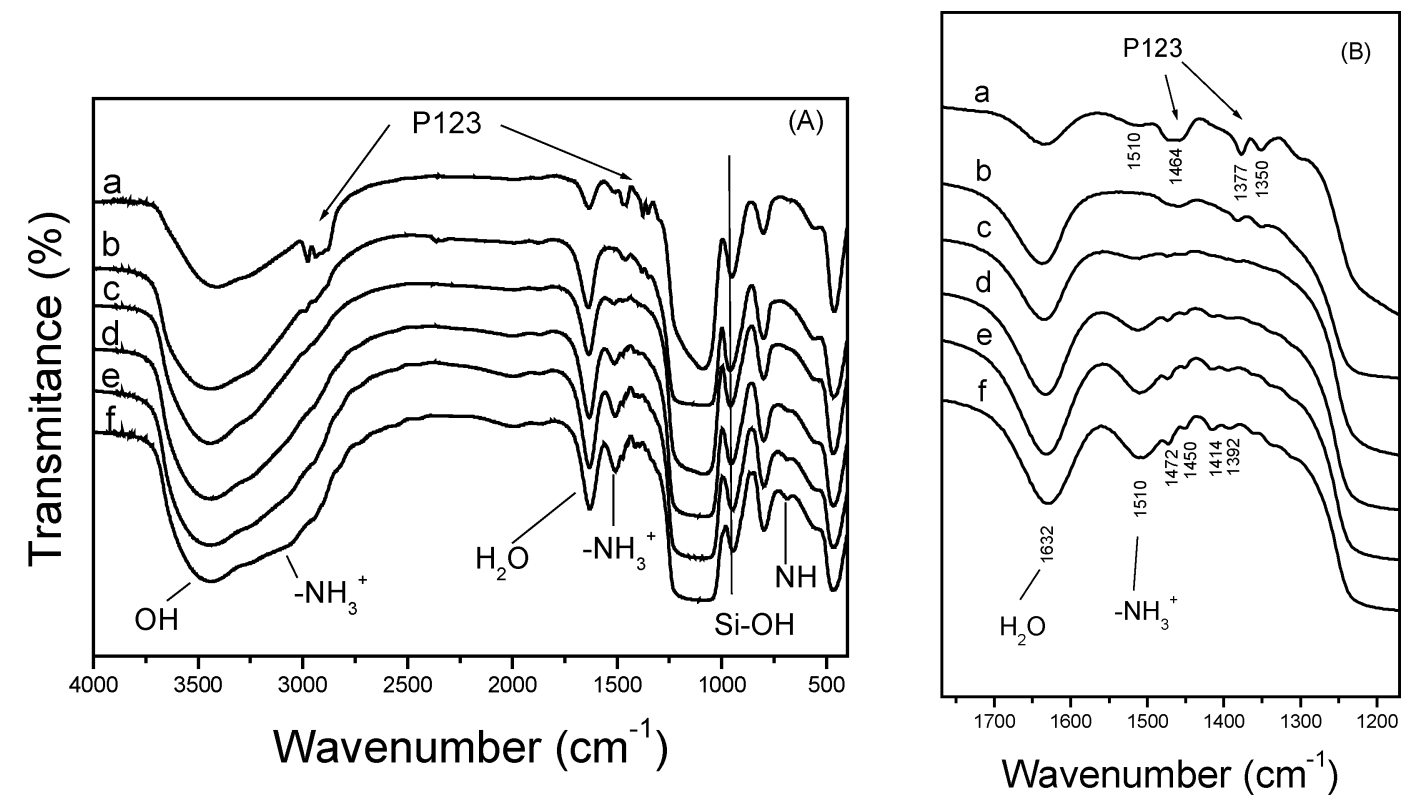

Figure 7. FTIR spectra of (a) as-synthesized $10 \% \mathrm{SBA}-\mathrm{NH}_{2}$ and the ethanol extracted $\mathrm{SBA}-\mathrm{NH}_{2}$ with different concentrations of aminopropyl groups in the initial mixture: (b) $0 \%$, (c) $5 \%$, (d) $10 \%$, (e) $15 \%$, and (f) $20 \%$. (A) Full range spectra. (B) Enlarged portion in $1200-1750 \mathrm{~cm}^{-1}$. 


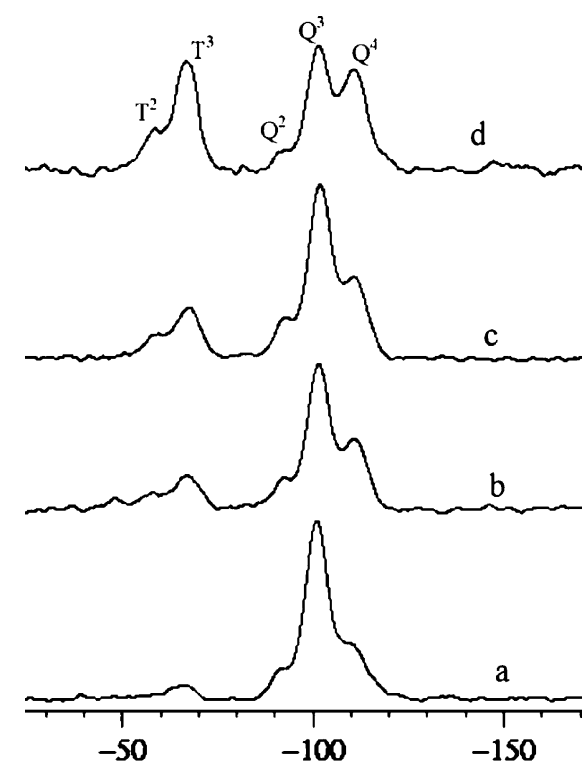

Figure 8. ${ }^{29} \mathrm{Si} \mathrm{CP}$ MAS NMR spectra of ethanol extracted SBA$\mathrm{NH}_{2}$ with different amounts of APTES in the initial mixture: (a) $5 \%$, (b) $10 \%$, (c) $15 \%$, and $20 \%$.

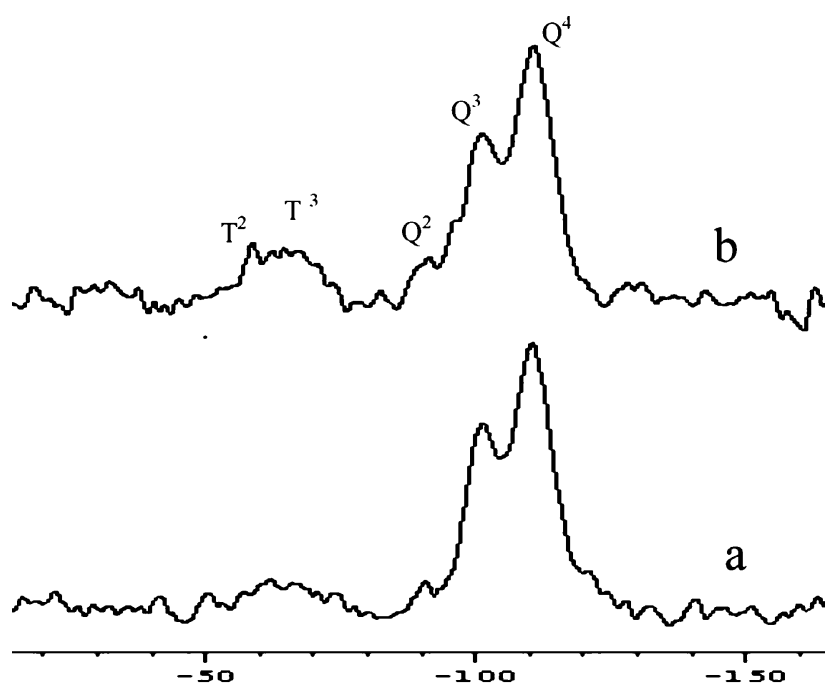

Chemical shift (ppm)

Figure 9. ${ }^{29} \mathrm{Si} \mathrm{NMR}$ spectra of ethanol extracted $\mathrm{SBA}-\mathrm{NH}_{2}$ with different aminopropyl groups in the initial mixture: (a) $10 \%$ and (b) $20 \%$.

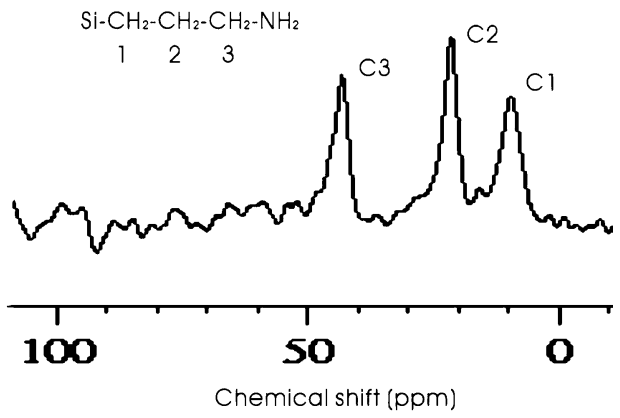

Figure 10. ${ }^{13} \mathrm{C}$ CP MAS NMR spectra of the ethanol extracted SBA$\mathrm{NH}_{2}$ with aminopropyl groups of $10 \%$ in the initial mixture.

preparation procedure. Besides, no peaks corresponding to surfactant P123 in the range of $67-77 \mathrm{ppm}$ implies the complete removal of surfactant P123 during extraction. ${ }^{38}$ That is also supported by TG analysis and IR spectra.
TABLE 4: Knoevenagel Reaction of Carbonyl Compounds $(10 \mathrm{mmol})$ with Ethyl Cyanoacetate $(10 \mathrm{mmol})$ in Cyclohexane $(10 \mathrm{~mL})$ over $10 \% \mathrm{SBA}-\mathrm{NH}_{2}(0.15 \mathrm{~g})^{a}$

\begin{tabular}{|c|c|c|c|c|}
\hline reaction & $\mathrm{R}$ & $\mathrm{R}^{\prime}$ & $\begin{array}{l}\text { time } \\
(\mathrm{h})^{c}\end{array}$ & $\begin{array}{l}\text { yield } \\
(\%)^{b, c}\end{array}$ \\
\hline 1 & $\mathrm{C}_{6} \mathrm{H}_{5}$ & $\mathrm{H}$ & $1(36)$ & $>99$ (94) \\
\hline 2 & $\mathrm{C}_{4} \mathrm{H}_{9}$ & $\mathrm{Me}$ & 8 & 89.3 \\
\hline 3 & Et & Et & $8(30)$ & $69.4(89)$ \\
\hline 4 & $\mathrm{C}_{3} \mathrm{H}_{7}$ & Et & 8 & 69.6 \\
\hline 5 & $\mathrm{cC}_{5} \mathrm{H}_{10}$ & & $3(12)$ & $>99(70)$ \\
\hline 6 & $\mathrm{C}_{6} \mathrm{H}_{5}$ & $\mathrm{Me}$ & 24 & 50.3 \\
\hline
\end{tabular}

${ }^{a}$ The removal of water was not carried out in the reaction procedure. ${ }^{b} n$-Dodecane as internal standard. ${ }^{c}$ Data in parentheses are from ref 23; reaction conditions: $20 \mathrm{mmol}$ of carbonyl compounds, $20 \mathrm{mmol}$ of ethyl cyanoacetate, $25 \mathrm{~mL}$ of cyclohexane, $82{ }^{\circ} \mathrm{C}$.

3.2. Catalytic Reactions. The catalytic performance of aminopropyl-functionalized SBA-15 was examined in basecatalyzed reactions. Before the reaction, the aminopropylfunctionalized materials were treated with TMAOH to remove the residue $\mathrm{Cl}^{-}$ions and to neutralize the protonated amine groups in the sample. The physical properties, texture, and amine contents of the treated materials were found to be almost unchanged. Figure 2 demonstrates that the well ordering of the SBA-15 pore structure was retained after $10 \% \mathrm{SBA}-\mathrm{NH}_{2}$ was treated with $0.2 \mathrm{M}$ methanol solution of TMAOH.

It is well-known that pore diameter of the solid catalysts has great influence for catalytic reactions proceeded in liquid phase. The large mesopores of SBA-15 were expected to facilitate the diffusion of reactants, products, and solvents encountered in the liquid-phase reactions. Table 4 displays the results of the Knoevenagel condensation of aldehyde or ketones with ethyl cyanoacetate over $10 \% \mathrm{SBA}-\mathrm{NH}_{2}$ catalyst. For comparison, some of the reaction results using aminopropyl-functionalized MCM-41 with a similar amine content $\left(1.2 \mathrm{mmol} \mathrm{g}^{-1}\right)$ under similar reaction conditions reported in the literature are given in parentheses. ${ }^{23}$ All the reactions were found to proceed to the olefin products and no intermediate alcohols or other side products were detected. It was noticed in Table 4 that aldehyde and cycloketone gave the highest yield, whereas aromatic ketone have the lowest yield. The reaction activities decrease in the order of aldehyde $>$ cycloketone $>$ aliphatic ketone $>$ aromatic ketone. That is attributed to the steric hindrance around the carbonyl group in the addition reaction. In comparison to that over MCM-41 of similar amine loading, $\mathrm{SBA}-\mathrm{NH}_{2}$ gave higher activities in these reactions, in light of the product yield and the time period needed in the reaction. The relatively larger pore size of SBA-15 is considered to facilitate the diffusion of reactants to the catalytic active sites.

We also tested the condensation and subsequent intramolecular Michael addition of benzaldehyde (A) and 2'-hydroxyacetonphenone (B) to flavanone (D) at $140{ }^{\circ} \mathrm{C}$. The results showed very high catalytic activity and selectivity to flavanone in both organic solutions and solvent-free condition (Table 5). Especially, the elimination of organic solvents is a frequent goal in green chemistry and the aminopropyl-functionalized SBA15 catalyst showed high activity in solvent free condition. When the $\mathrm{A} / \mathrm{B}$ molar ratio was increased from 1 to 1.5 , the conversion of B increased from $84 \%$ to $92 \%$ and the selectivity to D was retained around $70 \%$. From $\mathrm{GC}-\mathrm{MS}$ analysis, no products other than $\mathrm{C}$ and $\mathrm{D}$ were formed in the reaction. When the used 
TABLE 5: Reaction of Benzaldehyde and $2^{\prime}$-Hydroxyacetophenone over $0.15 \mathrm{~g}$ of $10 \% \mathrm{SBA}-\mathrm{NH}_{2}$ at $140{ }^{\circ} \mathrm{C}$ for $8 h^{a}$

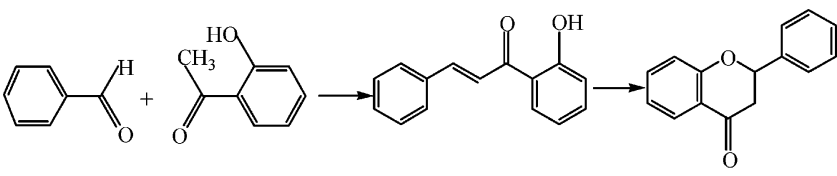

\begin{tabular}{cclcc} 
A & \multicolumn{1}{c}{ B } & \multicolumn{2}{c}{ C } & D \\
\hline reaction & $\begin{array}{c}\text { A/B } \\
\text { (molar ratio) }\end{array}$ & \multicolumn{1}{c}{ solvent $^{b}$} & $\begin{array}{c}\text { conv of B } \\
(\%)\end{array}$ & $\begin{array}{c}\text { select. to D } \\
(\%)\end{array}$ \\
\hline 1 & 1 & dimethyl sulfoxide & 52 & 68 \\
2 & 1 & benzonitrile & 35 & 48 \\
3 & 1 & nitrobenzene & 52 & 39 \\
4 & 1 & $c$ & 84 & 71 \\
5 & 1.5 & $c$ & 92 & 69 \\
6 & 1.5 & $d$ & 81 & 68
\end{tabular}

${ }^{a}$ Products in reactions $1-3$ were analyzed by GC, using $n$-dodecane as internal standard. Products in reactions 4-6 were diluted with dimethyl sulfoxide, followed by GC analysis. Reaction conditions: 10 mmol of A, 10 or $15 \mathrm{mmol}$ of B. ${ }^{b} 5 \mathrm{~mL}$ of solvent. ${ }^{c}$ Without solvent. ${ }^{d}$ Reuse the catalyst without solvent.

catalyst was reused after it was washed with ethanol and dried at $120{ }^{\circ} \mathrm{C}$, slightly lower conversion of $\mathrm{B}(81 \%$ versus $92 \%)$ and similar selectivity to $\mathrm{D}$ were observed (Table 5). The decrease in conversion is probably due to the incomplete removal of absorbed species from the active sites by ethanol. On the other hand, the same reaction using pure siliceous SBA15 , which was also pretreated with methanol solution of $0.2 \mathrm{M}$ tetramethylammonium hydroxide, as catalyst gave very low conversion (3\%) of B and $68 \%$ selectivity of D. These results confirm that the catalytic active sites in amino-functionalized SBA-15 are the aminopropyl groups instead of any surface $\mathrm{Si}-$ $\mathrm{O}^{-}$groups if they were present.

\section{Conclusions}

Well-ordered aminopropyl-functionalized SBA-15 with amino loading up to $16 \%$ was synthesized by co-condensation of TEOS and APTES using P123 as pore-directing agent under acid condition. Prehydrolysis of TEOS before the addition of APTES has great effect on the formation of aminopropyl-modified SBA15 mesoporous materials. The resultant materials show good crystallographic order, large uniform pore size, and high surface area. Nevertheless, the long-range ordering of mesoporous structure of the modified materials decreased with the increase in APTES concentration in the initial mixture. When used as a catalyst in liquid-phase reactions, the aminopropyl-functionalized SBA-15 gave very high yields in Knoevenagel reaction of carbonyl compounds with ethyl cyanoacetate in cyclohexane and in the condensation reaction of benzaldehyde and 2'hydroxyacetophenone to flavanone. In comparison with aminopropyl-modified MCM-41 of smaller pore size, SBA- $\mathrm{NH}_{2}$ with similar loading of amino groups shows better catalytic performance as a base catalyst.

Acknowledgment. This project was supported by the National Science Council, Taiwan.

\section{References and Notes}

(1) Kresge, C. T.; Leonowicz, M. E.; Roth, W. J.; Vartuli, J. C.; Beck, J. S. Nature 1992, 359, 710.

(2) Beck, J. S.; Vartuli, J. C.; Roth, W. J.; Leonowicz, M. E.; Kresge, C. T.; Schmitt, K. D.; Chu, C. T. W.; Olson, D. H.; Sheppard, E. W.; McCullen, S. B.; Higgins, J. B.; Schlenker, J. L. J. Am. Chem. Soc. 1992 114,10834 .

(3) Rodriguez, I.; Iborra, S.; Corma, A.; Rey, F.; Jordá, J. L. Chem. Commun. 1999, 593.

(4) Stein, A. Adv. Mater. (Weinheim. Ger.) 2003, 15, 763.

(5) Mbaraka, I. K.; Radu, D. R.; Lin, V. S.-Y.; Shanks, B. H. J. Catal. 2003, 219, 329

(6) Dai, S.; Burleigh, M. C.; Shin, Y.; Morrow, C. C.; Barnes, C. E.; Xue, Z. Angew. Chem., Int. Ed. Engl. 1999, 38, 1235.

(7) Yoshitake, H.; Yokoi, T.; Tatsumi, T. Chem. Mater. 2003, 15, 1713.

(8) Lin, V. S. Y.; Lai, C. Y.; Huang, J.; Song, S. A.; Xu, S. J. Am. Chem. Soc. 2001, 123, 11510.

(9) Huh, S.; Chen, H. T.; Wiench, J. W.; Pruski, M.; Lin, V. S. Y. J. Am. Chem. Soc. 2004, 126, 1010.

(10) Macquarrie, D. Chem. Commun. 1996, 16, 1961.

(11) Margollese, D.; Melero, J. A.; Christianesn, S. C.; Chmelka, B. F.; Stucky, G. D. Chem. Mater. 2000, 12, 2448

(12) Corriu, R. J. P.; Datas, L.; Guari, Y.; Mehdi, A.; Reyé, C.; Thieuleux, C. Chem. Commun. 2001, 763. 2472

(14) Wang, Y.; Zibrowius, B.; Yang, C.; Spliethoff, B.; Schüth, F. Chem Commun. 2004, 46.

(15) Shah, J.; Kim, S. S.; Pinnavaia, T. J. Chem. Commun. 2004, 572.

(16) Burleigh, M. C.; Markowitz, M. A.; Spector, M. S.; Gaber, B. P. Chem. Mater. 2001, 13, 4760.

(17) Diaz, I.; Pariente, J. P. Chem. Mater. 2002, 14, 4641.

(18) Goto, Y.; Inagaki, S. Chem. Commun. 2002, 2410.

(19) Llusar, M.; Monros, G.; Roux, C.; Pozzo, J. L.; Sanchez, C. J. Mater. Chem. 2003, 13, 2505

(20) Yokoi, T.; Yoshitake, H.; Tatsumi, T. J. Mater. Chem. 2004, 14 951.

(21) Beaudet, L.; Hossain, K. Z.; Mercier, L. Chem. Mater. 2003, 15 , 327.

(22) Walcarius, A.; Delacote, C. Chem. Mater. 2003, 15, 4181.

(23) Macquarrie, D. J.; Jackson, D. B. Chem. Commun. 1997, 1781

(24) Utting, K. A.; Macquarrie, D. J. New J. Chem. 2000, 24, 591.

(25) Brunel, D.; Fajula, F.; Nagy, J. B.; Deroide, B.; Verhoef, M. J.; Veum, L.; Peters, J. A.; Van Bekkum, H. Appl. Catal. A: General 2001, 213,73 .

(26) Macquarrie, D. J.; Jackson, D. B.; Mdoe, J. E. G.; Clark, J. H. New J. Chem. 1999, 23, 539 .

(27) Chong, A. S. M.; Zhao, X. S. J. Phys. Chem. B 2003, 107, 12650.

(28) Yiu, H. H. P.; Wright, P. A.; Botting, N. P.; J. Mol. Catal. B Enzym. 2001, 15, 81

(29) Marler, B.; Oberhagemann, U.; Vortmann, S.; Gies, H. Microporous Mater. 1996, 6, 375.

(30) Burleigh, M. C.; Markowitz, M. A.; Spector, M. S.; Gaber, B. P. J. Phys. Chem. B 2001, 105, 9935.

(31) Zhao, D.; Feng, J.; Huo, Q.; Melosh, N.; Frederichson, G. H.; Chmelka, B. F.; Stucky, G. D. Science 1998, 279, 548.

(32) Zhao, X. S.; Lu, G. Q.; Whittaker, A. K.; Millar, G. J.; Zhu, H. Y ; J. Phys. Chem. B 1997, 101, 6525 .

(33) Hall, S. R.; Fowler, C. E.; Lebeau, B.; Mann, S. Chem. Commun 1999, 201

(34) Sartori, G.; Bigi, F.; Maggi, R.; Sartorio, R.; Macquarrie, D. J.; Lenarda, M.; Storaro, L.; Coluccia, S.; Martra, G. J. Catal. 2004, 222, 410.

(35) Shriner, R. L.; Hermann, C. K. F.; Morril, T. C.; Curtin, D. Y.; Fuson, R. C. The Systematic Identification of Organic Compounds, 7th ed.; John Woley \& Sons: New York, 1998.

(36) White, L. D.; Tripp, C. P. J. Colloid Interface Sci. 2000, 232, 400.

(37) Wang, Y. Q.; Yang, C. M.; Zibrowius, B.; Spliethoff, B.; Linden, M.; Schüth, F. Chem. Mater. 2003, 15, 5029.

(38) Yang, C.; Zibrowius, B.; Schüth, F. Chem. Commun. 2003, 1772 